\title{
Paper Search for Chelyabinsk Meteorite Fragments in Chebarkul Lake Bottom (GPR and Magnetic Data)
}

\author{
Vladimir Buzin ${ }^{1}$, Dmitry Edemsky ${ }^{1}$, Sergey Gudoshnikov ${ }^{1}$, Vladimir Kopeikin ${ }^{1}$, Pavel Morozov ${ }^{1}$, \\ Alexey Popov ${ }^{1}$, Igor Prokopovich ${ }^{1}$, Vladimir Skomarovsky ${ }^{1}$, Nikolay Melnik ${ }^{2}$, Andrey Berkut ${ }^{3}$, \\ Sergey Merkulov ${ }^{3}$, Pavel Vorovsky ${ }^{3}$, and Leonid Bogolyubov ${ }^{3}$ \\ ${ }^{1}$ IZMIRAN, Troitsk, Moscow, Russia \\ ${ }^{2}$ FIAN, Moscow, Russia \\ 3 JSC “Company VNIISMI”, Moscow, Russia
}

https://doi.org/10.26636/jtit.2017.120817

\begin{abstract}
The paper summarizes experimental efforts of the Pushkov Institute of Terrestrial Magnetism, Ionosphere and Radio Wave Propagation (IZMIRAN) undertaken in search of the biggest part of Chelyabinsk meteorite in the bottom of lake Chebarkul, South Ural, Russia, and to estimate the ecological effects of its subsequent excavation.
\end{abstract}

Keywords-Chelyabinsk meteorite, Ground Penetrating Radar.

\section{Introduction}

The Chelyabinsk meteoroid (February 15, 2013) with an estimated initial mass of about 10.000 tons was probably the biggest space object entering the Earth's atmosphere during the last 100 years. It released its kinetic energy, equivalent to a 500,000 tons TNT explosion, into a bright flash at a height of about $25 \mathrm{~km}$ (Fig. 1) and a large shock wave causing broken roofs and windows in an about $50 \times 100 \mathrm{~km}$ area of Chelyabinsk region. Happily, no industrial object was touched, and hundreds of people received minor injuries. Many small meteorites produced ice carrots in the snow covering neighboring fields. The biggest part of the meteoroid landed in the western part of Chebarkul Lake

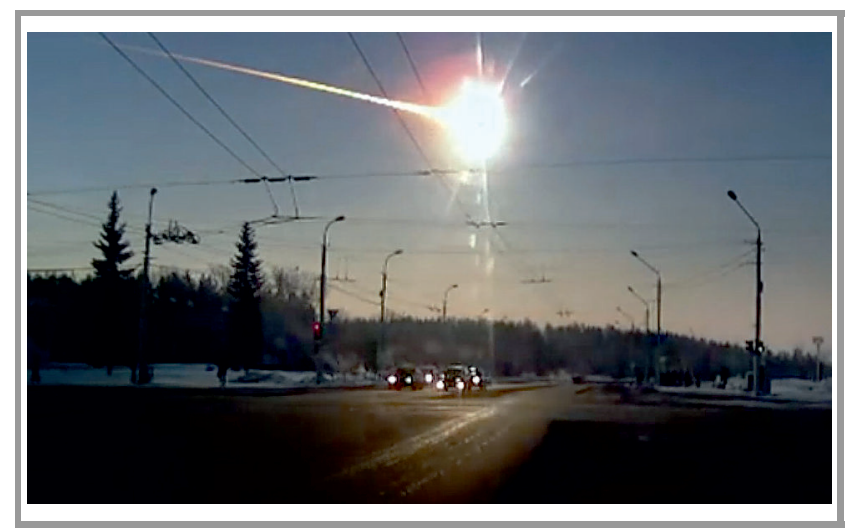

Fig. 1. Chelyabinsk bolide. (See color pictures online at www.nit.eu/publications/journal-jtit)

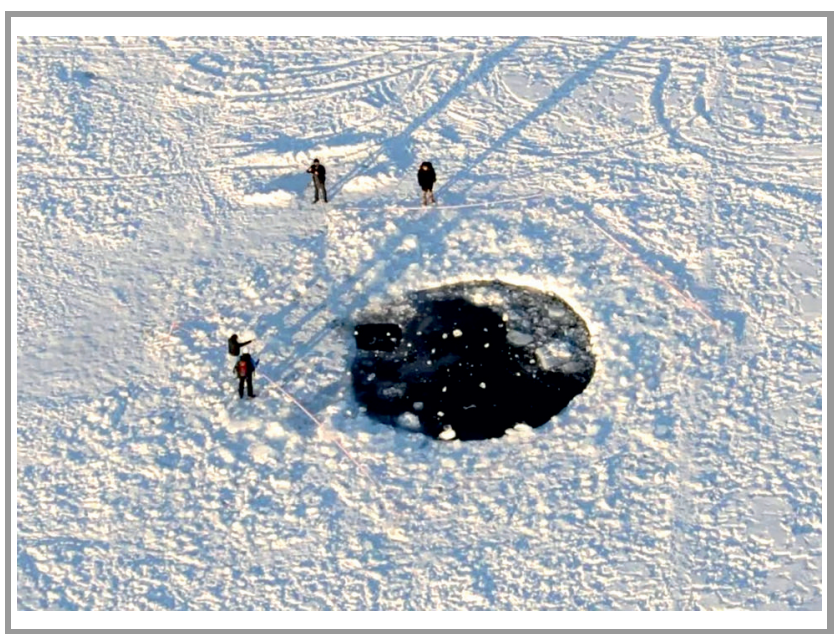

Fig. 2. Aerial photo of the meteorite ice-hole.

making an oval hole in the ice cover, up to $8 \mathrm{~m}$ in diameter (Fig. 2). The meteorite origin of the ice-hole was not commonly believed from the beginning, however Raman scattering analysis of the small chips, lifted from the lake bottom with a powerful magnet, and of micron-seized dust around the breach confirmed their space nature [1].

First divers' attempts to find the meteorite directly under the breach gave no effect (Fig. 3). The lake depth is about $10 \mathrm{~m}$ at the impact site, and the operations were hindered by the presence of a thick layer of loose silt, more than two-meter thick, according to their estimates. In order to reduce the search area, Ground Penetrating Radar (GPR) inspection of the lake bottom was performed from the ice surface by means of Loza-N GPR [2], [3]. Along with the information provided by Ural scientists and Czech colleagues [4], [5], the results of the IZMIRAN-VNIISMI GPR and magnetic surveys were used in preparing diving works undertaken later by the Aleut-Special Work Service Company [6] and resulting in the excavation of the biggest fragment of the space guest. 


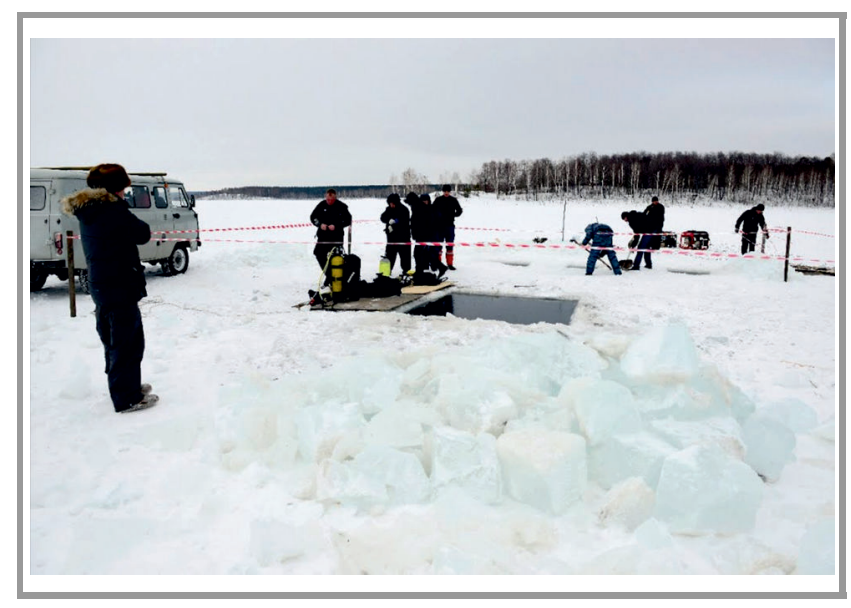

Fig. 3. First diving works from the ice cover.

\section{GPR Field Works}

Loza GPR was designed at Pushkov Institute of Terrestrial Magnetism, Ionosphere and Radio Wave Propagation (IZMIRAN) in relation with a planned space mission [7]. Afterwards its serial production has been undertaken by Joint-Stock Company VNIISMI [8]. The main distinctive feature of Loza GPR is energy accumulation in a single transmitted pulse which is generated by a capacitor rapidly discharging through a high-voltage hydrogen key. Its duration and shape depend on the transmitter antenna parameters. It must be non-resonant in order to avoid spurious "ringing" (generally, it is a resistively loaded dipole following classical Wu-King law). Due to resistive loading, Loza antenna radiation approaches an ideal one-period electromagnetic burst. Its low Q-factor is compensated by the high pulse energy. Serial Loza transmitters have 5 to $20 \mathrm{kV}$ peak voltage, the emitted pulse duration and energy being determined by the dipole length. Widely used in archeology and urban works "high-frequency" Loza-V sets with 0.5 to $1.5 \mathrm{~m}$ antennas have pulse central frequency in the range of $100-300 \mathrm{MHz}$ and provide penetration

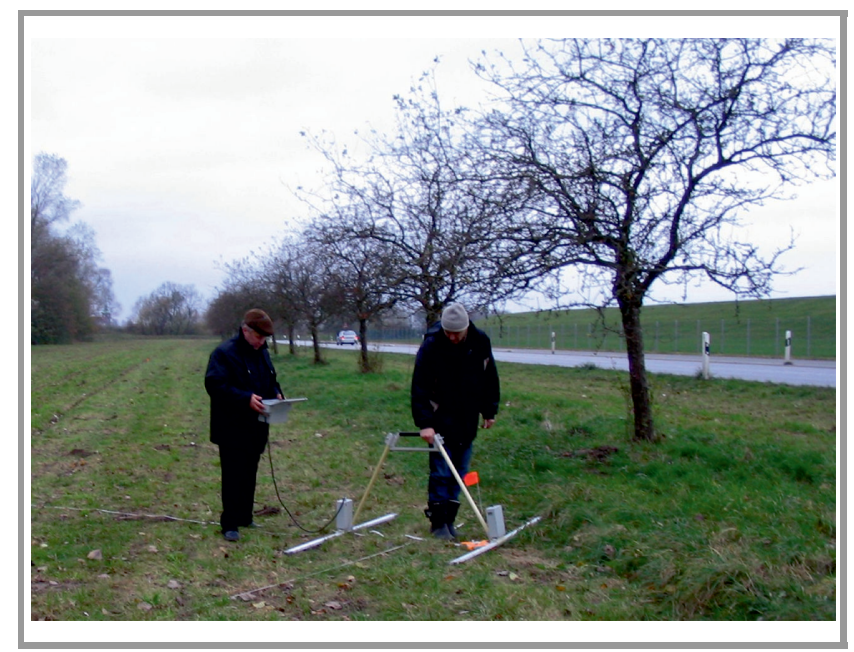

Fig. 4. Field operation with Loza-V GPR. depth of the order of 5-20 m, depending on ground conductivity (Fig. 4).

In order to radically increase the signal energy and penetration, the pulse spectrum in the low-frequency Loza-N sounder is shifted to the lowest part of the receiver frequency band: $10-50 \mathrm{MHz}$ [9]. A serial Loza-N set contains $3,6,10$, and 15 meter-long transmitter antennas mounted on a heavy-duty nylon band. Identical antennas are used in the receiver unit recording signals reflected from the subsurface layer interfaces or localized buried objects. The receiver works in a waiting mode, being switched on by the first coming aerial signal. The absence of interconnecting cables eliminates interference and assures high signalto-noise ratio. Loza central unit registers the waveform of the subsurface return pulse by means of a parallel set of high-rate comparators, with sampling frequency about $1 \mathrm{GHz}$. By repeating the measurement with input attenuation varying in a quasi-logarithmic scale, we obtain a 256-bit representation of the received signal in a $120 \mathrm{~dB}$ dynamic range.

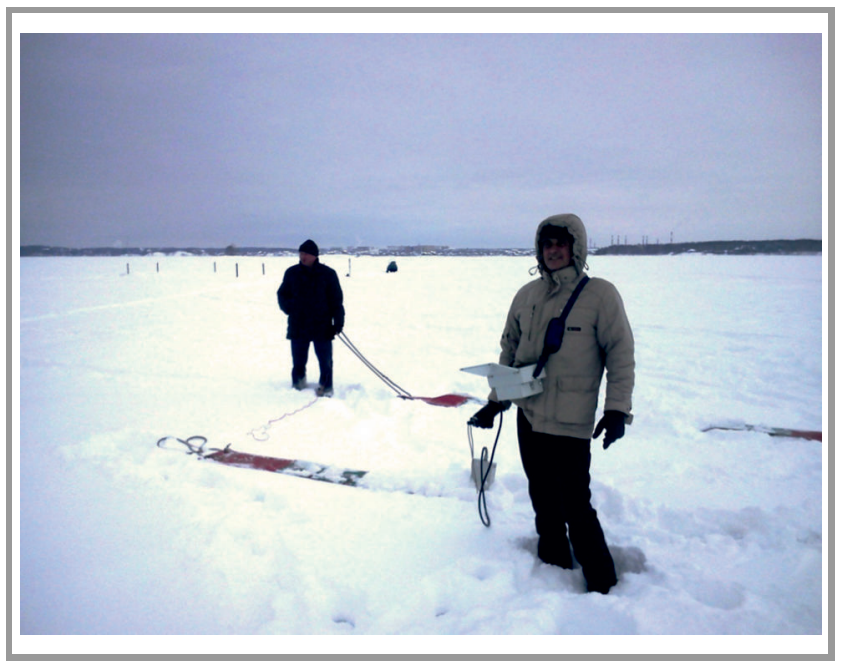

Fig. 5. Loza-N GPR survey around frozen ice-hole in lake Chebarkul.

Along with the aforementioned basic principles, the tight contact of the Loza-N flexible antennas with the ground and natural wave focusing towards electrically denser subsurface medium increase the GPR penetration depth. Compared with domestic and foreign analogs, Loza-N radar potential is increased by four orders of magnitude, allowing operation in highly conductive media, such as loam or wet clay. The sounding depth varies from a few meters to hundreds of meters, depending on the device model and medium properties. Taking into account the environment conditions (lake depth about $10 \mathrm{~m}$ and $1 \mathrm{~m}$ thickness of the ice/snow cover), low-frequency Loza-N model with 6-meter antennas was selected for GPR survey (Fig. 5). It could provide a sufficient probing depth and minimize interfering resonance effects. During three days of field works, March 12-14, 2013, the IZMIRAN-VNIISMI group (A. V. Popov, V. V. Kopeikin, S. V. Merkulov, V. A. Alek- 

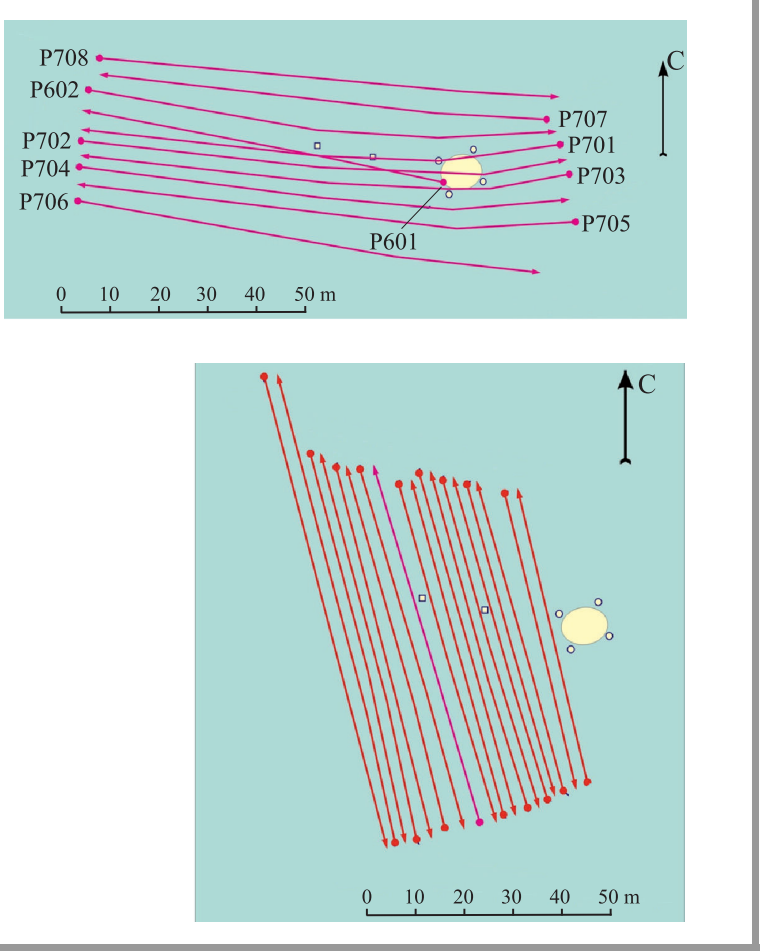

Fig. 6. GPR survey paths and ice-hole position.

seev) recorded 36 GPR scans covering a $100 \times 100 \mathrm{~m}$ area around the ice-hole (taking into account the meteorite trajectory, maximum attention was turned to the western neighborhood of the breach) - see Fig. 6.

These data, registered from the ice cover, reveal distinct details of the lake bottom shape indicating probable impact points of big meteorite fragments. Small chips were collected around and under the breach in order to identify possible future findings. The results of magnetic moment measurements of 3-millimeter sized chips [1] are consistent with the reported characteristics of other fragments of Chelyabinsk meteorite.

\section{Data Analysis}

In Fig. 7, an example of raw data recorded by Loza-N GPR and represented by means of Krot-1301 software [8] is given. The right panel displays the waveform of the radar return signal received at a selected point of GPR survey path (A-scan [10]).

In the left panel, the vertical cross-section (B-scan) taken along one of the survey paths is shown. The horizontal axis depicts the distance along the GPR path whereas the vertical axis displays the return signal arrival time in nanoseconds (right scale) and calculated reflector depth (left scale). Peculiar horizontal strips in the upper part of the plot correspond to the direct waves traveling from the transmitter to the receiver antenna with different velocities in the ice layer and pure water beneath the ice cover.

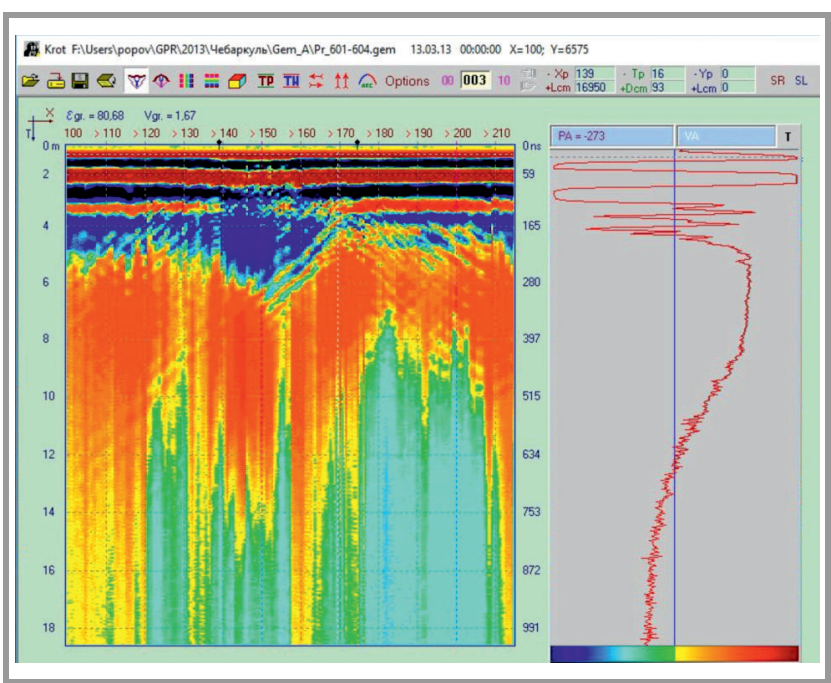

Fig. 7. Example of B-scan and selected radar return pulse (A-scan), Chebarkul lake, March 13, 2013.

The extended mono-polar pulses coming from greater depths are due to partial reflection from the gradual transition from pure water to the silt layer. Such a behavior is typical for the low-frequency Loza-N signals, which previously was attributed to the influence of ground conductivity. However, the numerical simulation shows that the main role in this case plays not conductivity but rather partial electromagnetic wave reflections from smooth gradients of the dielectric permittivity arising due to gradual increase of the solid fraction in the thick silt layer. A straightforward approach consists in numerical integration of the onedimensional (1D) wave equation [11]. A good qualitative agreement with the experimental data has been obtained for a model transition layer between pure water with relative dielectric permittivity $\varepsilon_{0}=81$ and a solid ground with $\varepsilon_{1}=10-20$, see the left panel of Fig. 8. Our model also

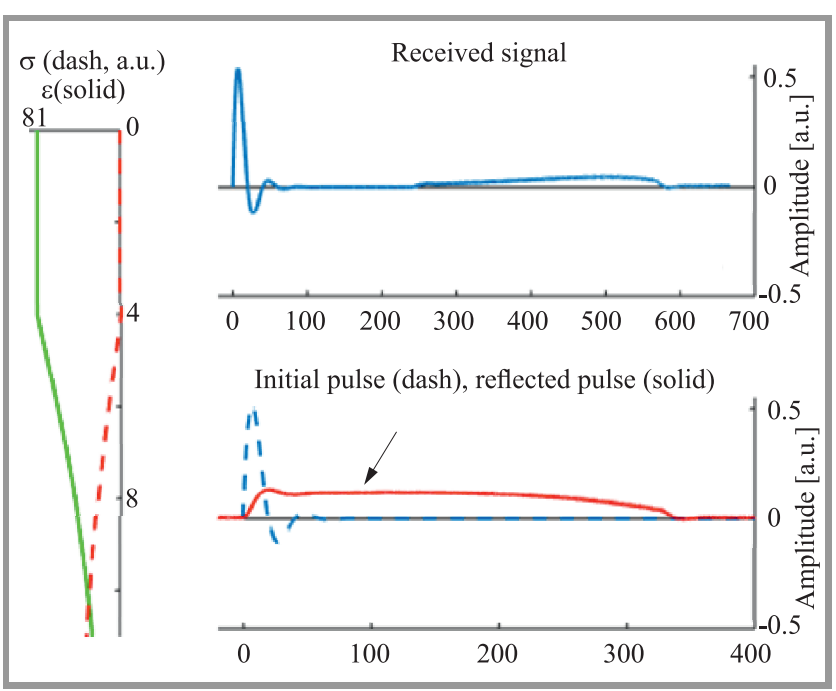

Fig. 8. Vertical profile of dielectric permittivity and soil conductivity (left), 1D numerical simulation of GPR return pulse (top), magnified reflected pulse (red, pointed by arrow) versus initial pulse (bottom). 
took into account a gradual increase of the medium conductivity from $\sigma_{0}=0$ to $\sigma_{1}=0.001 \mathrm{~S} / \mathrm{m}$. The duration of the model probing pulse is about $25 \mathrm{~ns}$, which is close to the physical Loza-N pulse duration.

The full waveform of the electric field registered by the sensitive GPR receiver placed on the water surface is shown in the upper panel of the figure. Along with the short initial pulse, a weak protracted signal appearing due to partial reflections from the vertical gradients of the dielectric permittivity can be noticed. In order to better visualize the reflected signal on the strong primary pulse background, a minor exponential amplification $\mathrm{e}^{\alpha t}$ has been introduced. Its waveform, shown in a magnified scale against the primary GPR pulse in the bottom panel of Fig. 8, is similar to the observed wave forms of low-frequency GPR probing, depicted in Fig. 7 (not taking into account the direct surface waves). In processing raw data with Krot-1301 software package, the characteristic points of the maximum amplitude variations of the reflected signal were interpreted as the interfaces of the non-uniform transition layer between pure water and the solid bottom ground. A qualitative understanding of partial reflections from the vertical permittivity gradients $\varepsilon^{\prime}(z)$ gives the time-domain version of the coupled Wentzel-Kramers-Brillouin (WKB) approximation [11]:

$$
g(s)=-\frac{1}{8} \int_{0}^{\stackrel{+}{z}(s)}\left(\frac{\varepsilon^{\prime}(z)}{\varepsilon^{\frac{3}{2}}(z)}\right)^{\prime} h[s-2 p(z)] \mathrm{d} z .
$$

Here, $s=c t$ is normalized propagation time, $g(s)-$ received EM signal, $h(s)=\int f(s) \mathrm{d} s$ is integral of the initial transmitted pulse $f(s)$, and $p(z)=\int_{0}^{z} \sqrt{\varepsilon(\xi)} \mathrm{d} \xi$ is optical path from the transmitter to the virtual reflection layer $z$. If the transmitted pulse length is small compared with the characteristic thickness of the transition layer, the integral (1) can be transformed to an explicit analytical expression [9]:

$$
g(s) \approx-\frac{I(s)}{8}\left[\varepsilon^{-\frac{1}{2}}\left(\frac{\varepsilon^{\prime}}{\varepsilon^{\frac{3}{2}}}\right)^{\prime}\right]_{z=z_{m}(s)},
$$

where $I(s)=\frac{1}{2} \int_{0}^{s} h(\xi) \mathrm{d} \xi$ and $z_{m}$ is the depth corresponding to the pulse roundtrip travel time $s \approx 2 p\left(z_{m}\right)$.

In this simplified $1 \mathrm{D}$ wave propagation model a number of the physical moments have been ignored, i.e. boundary effects at the water surface covered with a thick ice layer, the offset between the transmitter and receiver antennas, wave divergence and radiation pattern of the dipole antenna placed on the interface. Having taken into account these factors in an improved 2D propagation model we reach a good agreement with the experimental radar scans - see Fig. 9a-b, and make our simulation be suitable for the field data analysis.
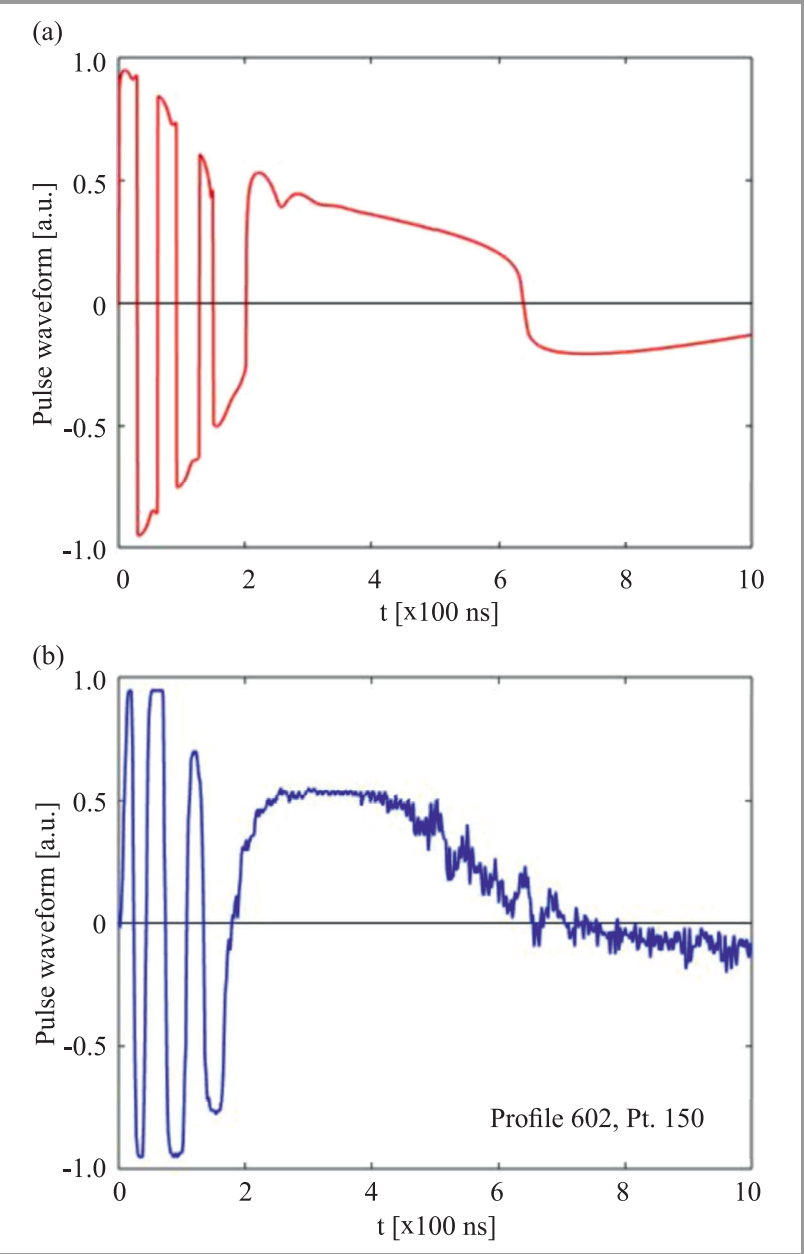

Fig. 9. (a) Numerical simulation using 2D coupled-WKB approximation and (b) experimental A-scan.

\section{Physical Considerations}

A remarkable feature of the GPR B-scan presented in Fig. 7 is a pronounced depression in the bottom curve, accompanied by a local thickening and structure change of the ice cover, in P602 cross-section at its intersection with P603 scan (Fig. 10). We put forward a guess that this anomaly was the result of a meteorite fragment impact onto the lake floor. This hypothesis conforms to the observational facts. The oblique trajectory of meteorite flight with azimuth of $280-290^{\circ}$ and small amount of ejected ice suggest that its major portion might be dragged down by the meteorite west of the hole and then float upward disturbing the structure of the ice cover above the impact crater. On the basis of these considerations, the GPR B-scans were analyzed in detail. A standard frequency windowing procedure implemented in Krot-1301 software package allows one to pick out the characteristic points on the signal plot (e.g. maxima of the derivative) and to bind them into a radio image of the reflecting boundaries. Figure 11 displays an example of such processing distinctly revealing the lake bottom shape and the aforementioned disturbance of the ice cover structure. The interfaces of the transition silt layer between clear wa- 


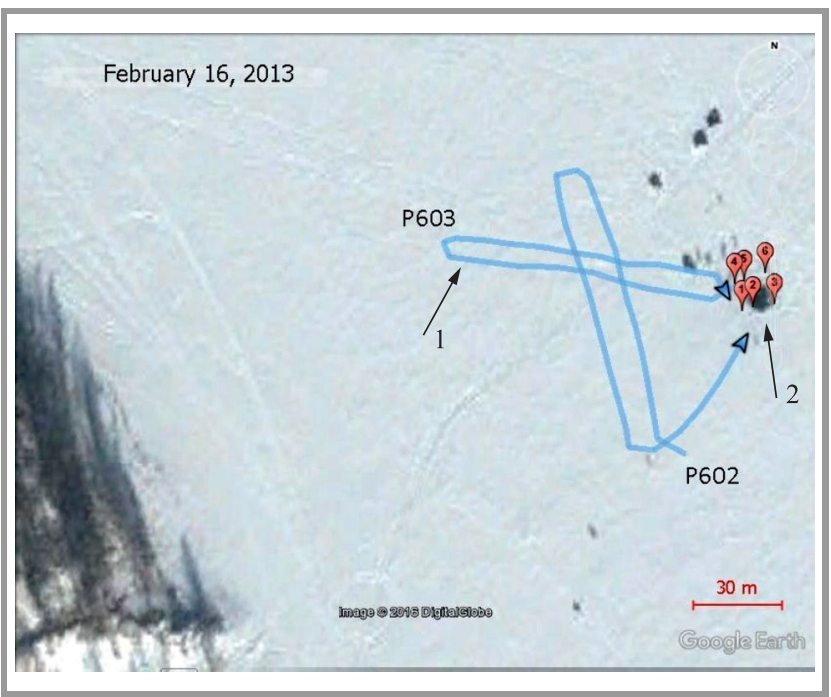

Fig. 10. Aerial photograph of the ice-hole. Crossing of P602 and P603 GPR paths (blue - arrow "1") shows probable meteorite fragment position in the lake bottom; red marks (arrow "2") - six stakes around the breach.

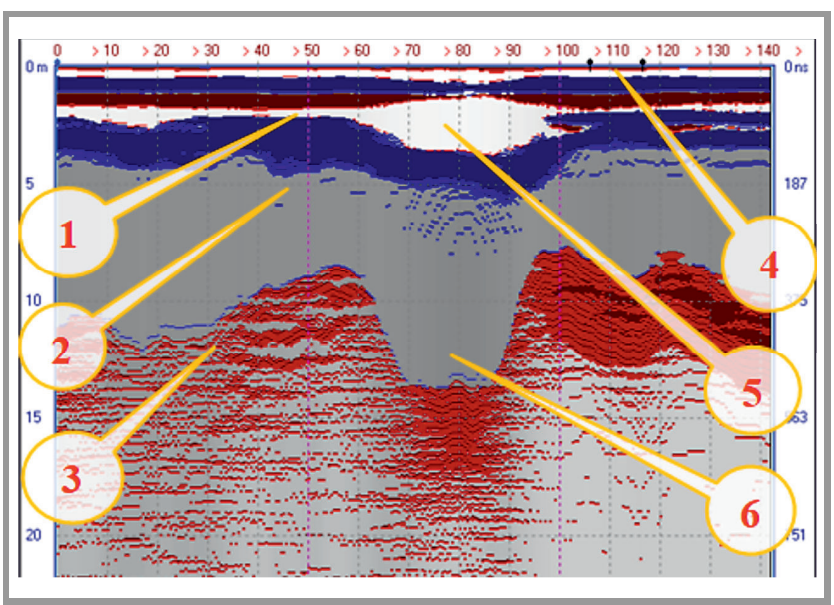

Fig. 11. B-scan along P602 track. Interpretation: 1 - ice layer, 2 - pure water and silt layer, 3 - hard bottom, 4 - ice-hole position, 5 - ice anomaly, 6 - meteorite crater.

ter and solid bottom are well seen. The hole produced in the ice cover by the meteorite impact, already frozen during our measurements, is pointed with black markers at the horizontal axis around the value $110 \mathrm{~m}$. The pronounced depression of the bottom curve, which was interpreted as a result of the meteorite collision with the hard lake bed, is observed $30 \mathrm{~m}$ to the west (between 70 and $90 \mathrm{~m}$ marks). The local violation of the surface wave structure above the dip can be related to the aforementioned thickening of the ice cover due to the ice mass floated upwards from the impact crater.

A similar anomaly is observed at the neighboring GPR paths, resulting in a three-dimensional (3D) reconstruction of the supposed meteorite crater (Fig. 12). The spotted pattern of the reconstructed bottom shape prompts a suggestion that the meteorite, when sinking into the lake water, could break into pieces following a ricochet trajectory [8].
The main crater position relative to the ice-hole, being consistent with the observational trajectory data, allowed us to recommend searching for a big fragment of Chelyabinsk meteorite in the aforementioned region of the Chebarkul lake floor.

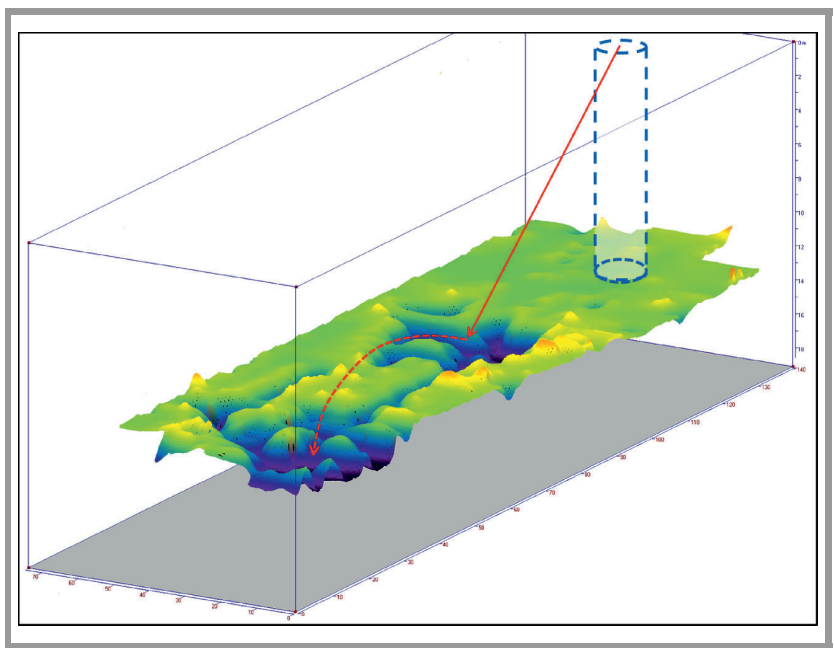

Fig. 12. 3D reconstruction of the hard bottom shape; dotted cylinder - ice-hole projection, arrows - possible meteorite fragments trajectories.

\section{Magnetometry and Meteorite Recovery}

Basing on the expected magnetic nature of the Chebarkul meteoroid fragment, several research groups performed magnetometric surveys of the supposed impact site. Just a week after the meteorite fall, February 20-21, 2013, Ovcharenko and Shchapov (Institute of Geophysics, Ural Branch of the Russian Academy of Sciences) performed magnetic mapping of the ice surface around the frozen icehole [4]. An overall distribution of the modulus of magnetic induction is presented in Fig. 13.

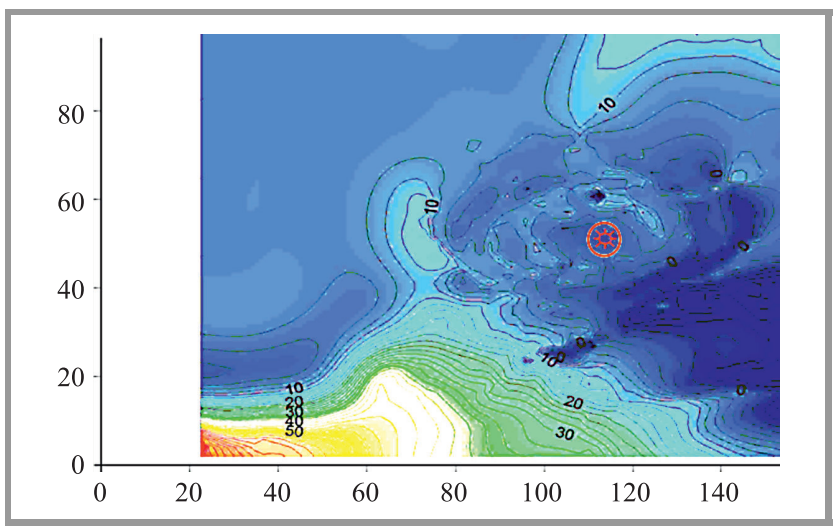

Fig. 13. Ural researchers' magnetic data [3].

The authors call the reader's attention to a weak positive horseshue-like anomaly c.a. 5-6 nT about $20 \mathrm{~m}$ west of the breach, which might be caused by the main fragments 
of the hondrite body. A strong negative linear anomaly of 40-50 nT, south-east of the ice-hole, evidently has no relation with the meteorite body and may have man-caused nature.

Two weeks later, a research group from the Charles University, Prague, led by Kletetschka, made surface magnetic field mapping showing a positive anomaly to the north-west of the breach that was interpreted as a purely geological effect [5]. The subsequent underwater magnetic survey with a submersible fluxgate magnetometer, performed in June 19-22, 2013, revealed two sharp peaks of magnetic induction, south-east of the ice-hole - see Fig. 14. However, these anomalies, centered at the $9 \mathrm{~m}$ depth, also might have technogenic origin.

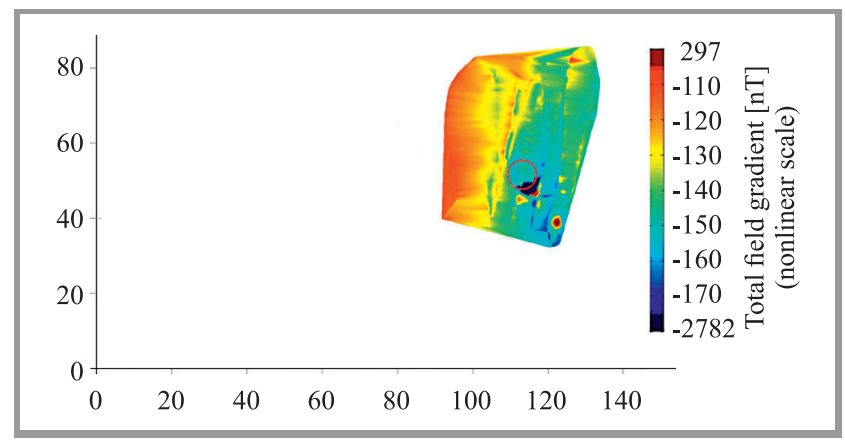

Fig. 14. Czech scientists' magnetic data [5] (submersible magnetometer).

The second IZMIRAN mission (Gudoshnikov, Skomarovskij, Buzin, Alekseev, April 2-5, 2013) performed magnetic survey of a rectangular portion of the ice surface $80 \times 30 \mathrm{~m}$ to the west of the ice-hole. The raw data (Fig. 15) exposed a regular increase of magnetic induction towards the west (coast effect, analogous to Fig. 14).

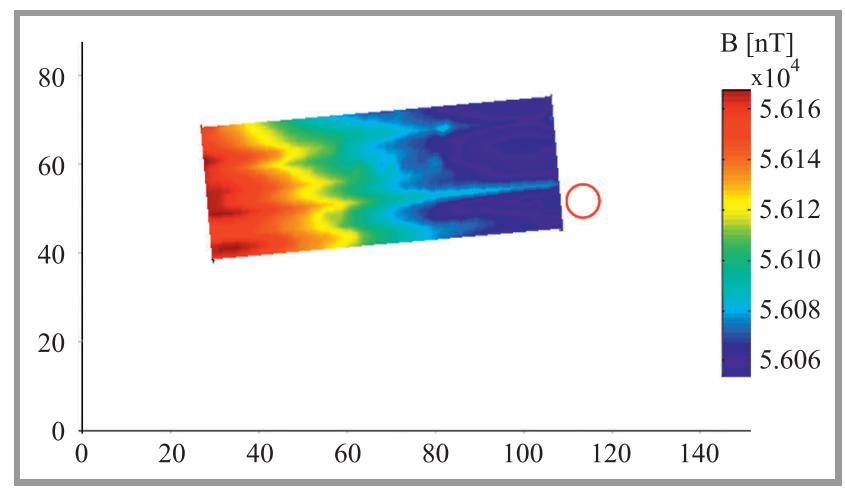

Fig. 15. IZMIRAN team magnetic data.

By subtracting the westward trend we obtain a map of local magnetic anomalies (Fig. 16) having much in common with the pattern of GPR back reflections (cf. Fig. 12). This similarity supports our guess at the meteorite fragments position in the lake bottom ground.

The results of the first IZMIRAN-VNIISMI GPR and magnetic surveys were submitted to the Ministry of Ecology of the Chelyabinsk Region Government having sponsored the

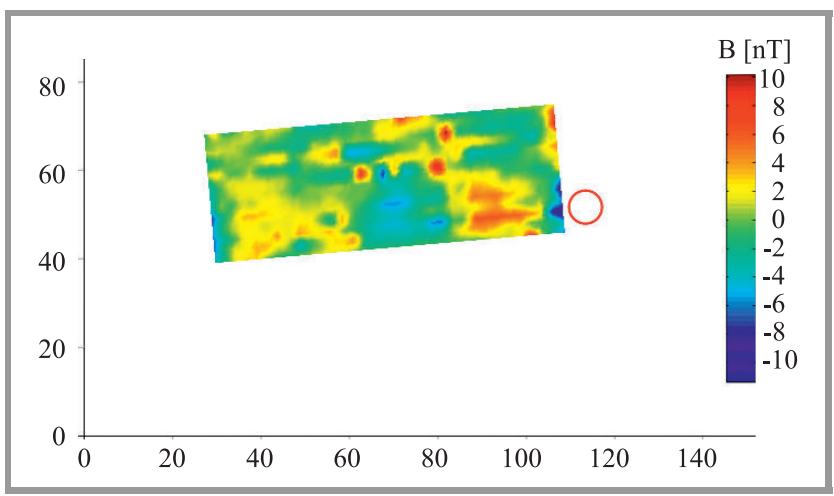

Fig. 16. Magnetic anomaly (coast effect removed).

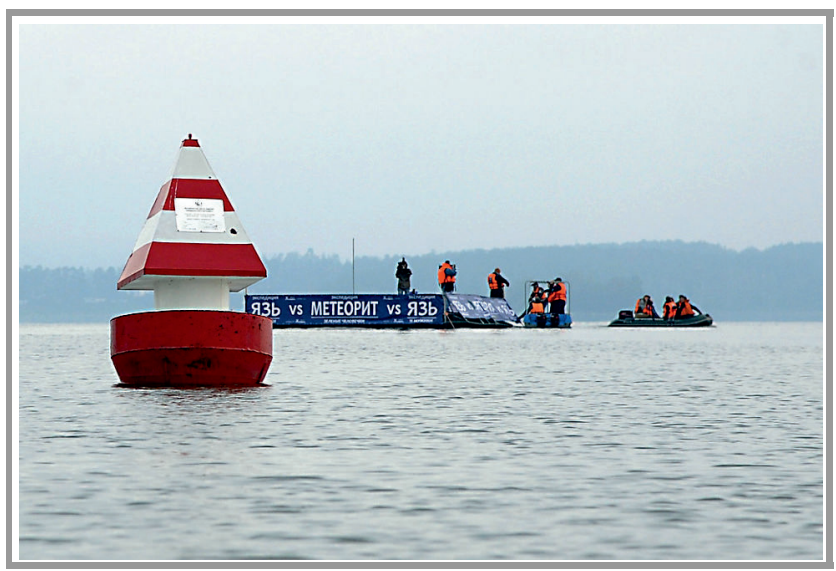

Fig. 17. Floating platform for diving works.

diving works undertaken during September-October 2013 by the Aleut-Special Work Service Company [6] - Fig. 17. The underwater works ended up in finding and digging up a $654 \mathrm{~kg}$ meteorite fragment. These endeavors are vividly depicted in the recently published book [12]. According to the presented data, the biggest piece has been extracted from the depth of about $18 \mathrm{~m}$, some 10 meter south-west of the breach. The main excavated meteorite fragment now is exposed in the Chelyabinsk Lore museum - Fig. 18. Its smaller parts, broken away during the diving works, have

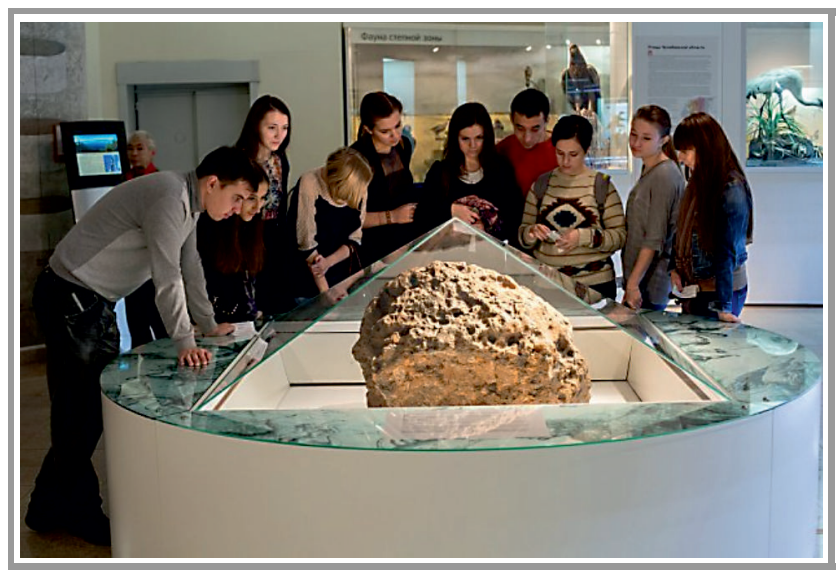

Fig. 18. Chebarkul meteorite fragment in the Chelyabinsk Lore Museum. 
been presented to different organizations that took part in the search for the meteorite [13].

Raman scattering analysis of the fragment presented to IZMIRAN - Fig. 19a, performed by Melnik [14], confirmed its mineral composition corresponding to ordinary chondrite LL5 and spectral identity with the small meteorite chips gathered from the ice cover and the bottom of lake Chebarkul immediately after the meteorite fall - Fig. 19b.

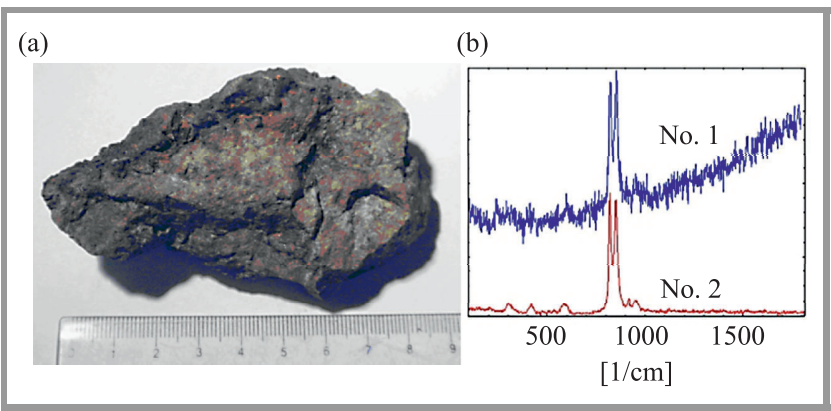

Fig. 19. (a) Fragment presented to IZMIRAN, (b) Olivine manifestation in Raman scattering spectra of IZMIRAN specimen (no. 1) and of a small chip from the ice-hole (no. 2).

The second IZMIRAN-VNIISMI GPR mission (Popov, Prokopovich, Vorovskij, Bogolyubov, December 18-20, 2013) revealed a pronounced dip in the western direction from the ice-hole (see Fig. 20). This anomaly can be identified as a result of Aleut's digging works. The survey was performed with the same 6-meter long Loza-N antennas from the thick ice cover. Its spatial resolution did not allow to resolve finer subsurface features.

Taking into account the continuing interest to the Chelyabinsk event, ecological concerns about lake Chebarkul condition and methodical problems of GPR measurements from the water surface, four years later the third IZMIRAN GPR mission was organized (Edemskij, Popov, Prokopovich, Bogolyubov, June 15-22, 2017). The main goal of the planned survey was to draw the bottom line left after the Aleut diving works and to detect possible subsurface objects. In order to provide better spatial resolution we should use shorter antennas. Basing on our previous expe-

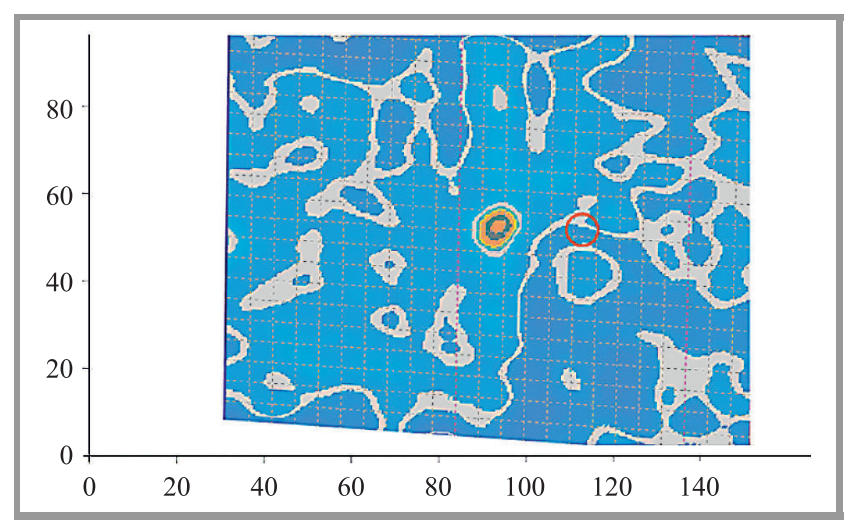

Fig. 20. Lake ground reflectivity according to second IZMIRAN GPR mission. rience, we first tried a standard Loza-V GPR transmitter and antenna set (Fig. 4) assuring 10-12 m penetration in a fresh lake water [15]. All the equipment could be placed in a hull of a small rowing boat allowing convenient through-water operation along a chaotic path controlled by GPS.

Unfortunately, the tests performed in the vicinity of the meteorite impact site (west coast of lake Chebarkul) had shown worse penetration, making Loza-V set useless at the depths exceeding $5 \mathrm{~m}$ - see Fig. 21.

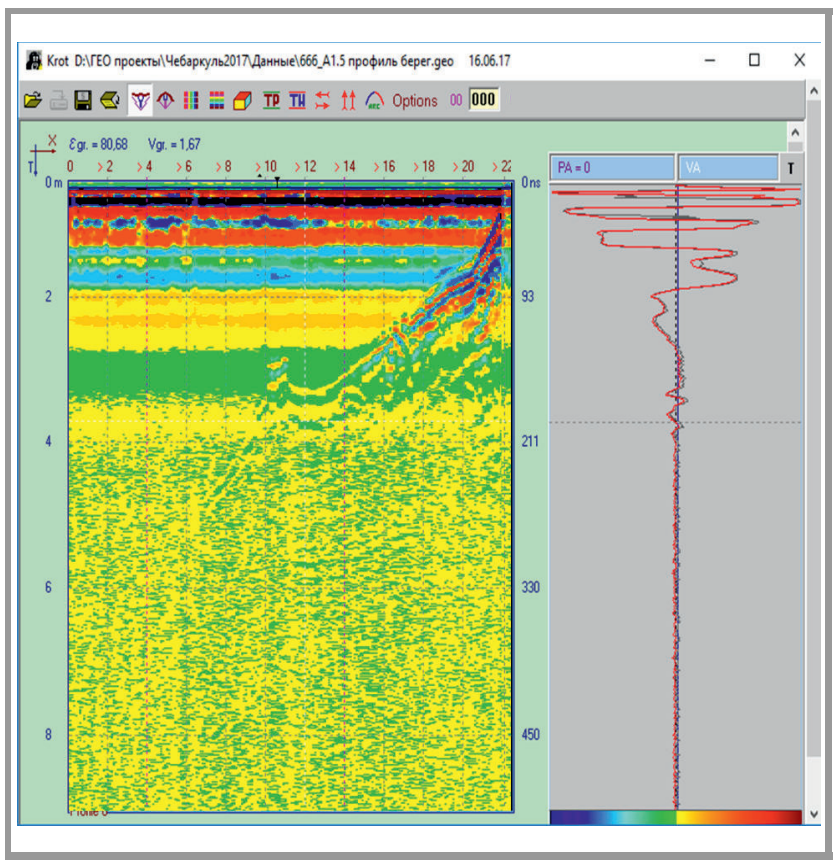

Fig. 21. Lake Chebarkul bottom line, Loza-V GPR (west coast).

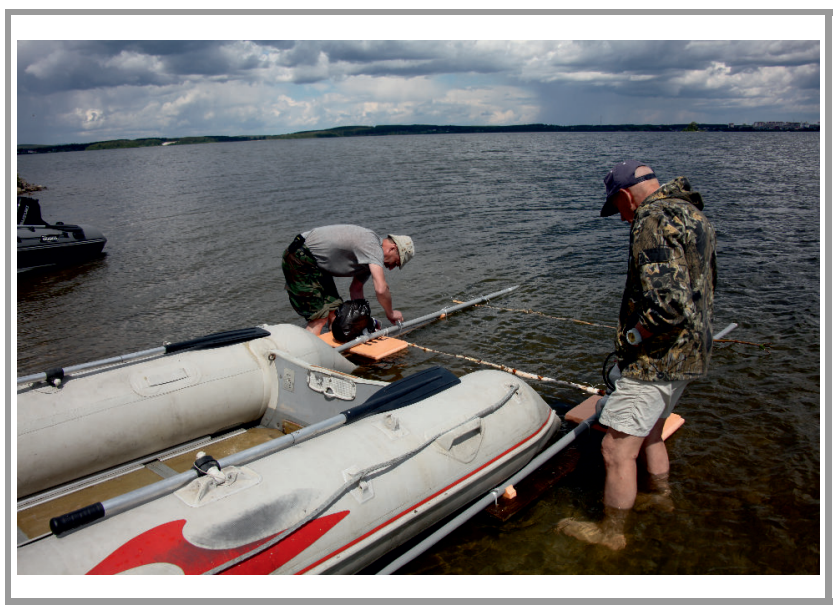

Fig. 22. Testing 4-m dipole antennas.

This result allows one to roughly estimate the electrical conductivity of the lake water. The additional linear electromagnetic wave attenuation $1640 \frac{\sigma}{\sqrt{\varepsilon_{r}}} \mathrm{~dB} / \mathrm{m}$ amounts to $120 \mathrm{~dB}$ (dynamic range of Loza receiver) on a roundtrip path of 10 meters for $\sigma: 0.066 \mathrm{~S} / \mathrm{m}$, which is in a good agreement with the hydrological data obtained after the meteorite fall [16]. 
Trying to overcome this limitation, we developed a homemade antenna set of intermediate $(4 \mathrm{~m})$ size but heavy rain storms did not allow us to complete the experiment.

\section{Conclusion}

The results of the first IZMIRAN-VNIISMI GPR survey (March 12-14, 2013) and the data of magnetic measurements performed by the next IZMIRAN expedition (April 2-5, 2013) from the ice surface revealed a pronounced anomaly, west of the breach left after Chelyabinsk meteorite fall into lake Chebarkul (February 15, 2013). Along with other research groups' data, they were used in preparing diving works undertaken during September 2013 by the Aleut-Special Work Service Company and sponsored by the Chelyabinsk region government. These works resulted in finding and lifting a big fragment of the meteorite (October 13, 2013). A part of the excavated space body presented to IZMIRAN was put to Raman scattering analysis at Lebedev Physical Institute (FIAN), conforming its mineral composition corresponding to ordinary chondrite (LL5). GPR survey performed by the third IZMIRAN mission (December 18-20, 2013) revealed a sharp dip in the lake bottom, probably a result of the digging operation. An attempt of detailed GPR inspection of the lake bottom undertaken in June 2017 did not give impressive results because of high conductivity of the lake water and bad weather conditions. However, among others, our GPR data and magnetic measurements prompt that a considerable mass of the meteorite matter may still reside in the lake Chebarkul bottom ground.

\section{Acknowledgment}

This publication is dedicated to the memory of Vladimir Alekseev who participated in two IZMIRAN expeditions, collecting small meteorite particles and performing their physical-chemical analysis. The authors are grateful to E. V. Korolkov and Chebarkul city administration for technical support of the field works. This paper is written as a contribution to the Special Issue "Recent Progress in Electromagnetic Theory and its Applications" organized by the COST Action TU1208 "Civil engineering applications of Ground Penetration Radar".

$$
* * *
$$

Regretfully, one of the co-authors - Vladimir Kopeikin passed away during the process of article publication.

\section{References}

[1] V. A. Alekseev, A. I. Berkut, and N. N. Melnik, "Meteorite investigation by CRS method. Chelyabinsk meteorite and Tunguska phenomenon", in Raman Scattering - 85 Years of Research, A. N. Vtiurin, Ed. Krasnoyarsk: Institute of Physics, 2013, pp. $162-171$.
[2] V. V. Kopeikin et al., "Ground penetrating radar investigation of the supposed fall site of a fragment of the Chelyabinsk meteorite in lake Chebarkul", Geochemistry Int., vol. 51, no. 7, pp. 575-582, 2013.

[3] V. V. Kopeikin et al., "GPR inspection of the Chelyabinsk meteorite impact site at the Chebarkul lake bottom", in Proc. 15th Int. Conf. on Ground Penetrat. Radar GPR 2014, Brussels, Belgium, 2014, pp. 1054-1057.

[4] A. V. Ovcharenko and V. A. Shchapov, "Magnetic observations at the Chebarkul fragment of Chelyabinsk meteorite impact site", in Proc. Scient. Conf. "Chelyabinsk Meteorite, a Year on Earth", Chelyabinsk, Russia, 2014, pp. 294-300 (in Russian).

[5] G. Kletetschka, J. Vyhnanek, D. Kawasumiova, L. Nabelek, and V. Petrucha, "Localization of the Chelyabinsk meteorite from magnetic field survey and GPS data", IEEE Sensors J., vol. 15, no. 9, pp. 4875-4881, 2015.

[6] Aleut - Special Work Service [Online]. Available: http://www.aleut.ru

[7] V. V. Kopeikin, D. E. Edemsky, V. A. Garbatsevich, A. V. Popov, A. E. Reznikov, and A. Yu. Schekotov, "Enhanced power ground penetrating radars", in Proc. 6th Int. Conf. on Ground Penetrat. Radar GPR'96, pp. 152-154. Sendai, Japan, 1996.

[8] JSC VNIISMI [Online]. Available: www.geo-radar.ru

[9] A. I. Berkut, D. E. Edemsky, V. V. Kopeikin, P. A. Morozov, I. V. Prokopovich, and A. V. Popov, "Deep penetration subsurface radar: hardware, results, interpretation", in Proc. 9th Int. Symp on Adv. Ground Penetrat. Radar IWAGPR 2017, PS-2, 3_25, Edinbourgh, United Kingdom, 2017

(doi: 10.1109/IWAGPR.2017.7996052).

[10] D. J. Daniels, Ground Penetrating Radar. London: IEE, 2004.

[11] V. A. Vinogradov, V. V. Kopeikin, and A. V. Popov, "An approximate solution of 1D inverse problem", in Proc. 10th Int. Conf. on Ground Penetrat. Radar GPR 2004, Delft, Netherlands, 2004, pp. 95-98.

[12] Search and Excavation of Chelyabinsk Meteorite. South Ural Publishing House, 2015, ISBN 978-5-7688-1083-2 (in Russian).

[13] A. V. Kocherov and V. A. Tyumentsev, "Fragments of Chelyabinsk meteorite from Lake Chebarkul", in Proc. Scient. Conf. "Chelyabinsk Meteorite, a Year on Earth", Chelyabinsk, Russia, 2014, pp. 348-354 (in Russian).

[14] A. V. Popov and N. N. Melnik, "Notes on the search and characterization of Chelyabinsk meteorite", in Proc. 2nd Practical Scient. Conf. "Meteorites, Asteroids, Comets", Chebarkul, Russia, 2014, pp. 101-106. Theta Publ., Chelyabinsk, 2014 (in Russian).

[15] A. Popov, P. Morozov, D. Edemsky, F. Edemsky, B. Pavlovskij, and S. Zapunidi, "Expedient GPR survey schemes", in Proc. 11th Int. Radar Symp. IRS 2010, 8a-3, Inspec Acc. 11474488, Vilnius, Lithuania, 2010.

[16] S. G. Zakharov, Ecosystem of Lake Chebarkul Before and After Meteorite Fall. Chelyabinsk: Kraj Ra Publishers, 2014 (in Russian).

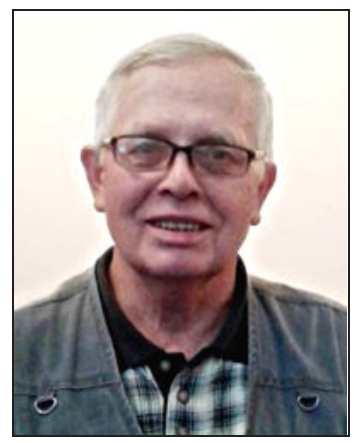

Vladimir Buzin graduated from Physical Department of Moscow State University in 1969. He is currently working in the Laboratory of Magnetic Cosmic Research, Pushkov Institute of Terrestrial Magnetism, Ionosphere and Radio Wave Propagation, Russian Academy of Sciences. His expertise is magnetic data processing, service and calibration of magnetic measuring installations and devices.

E-mail: buzin.40@mail.ru

IZMIRAN

4 Kaluzhskoye Hwy

Troitsk, Moscow 108840 Russia 


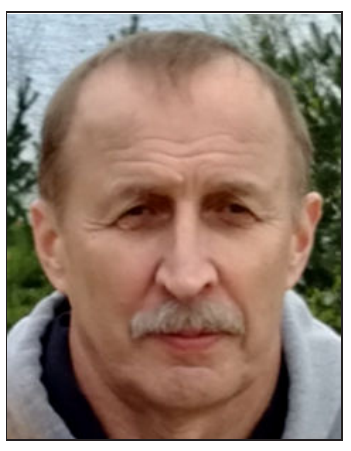

Dmitry Edemsky received his Ph.D. degree in Technical Sciences from Vinnytsa National Technical University in 1989. $\mathrm{He}$ works as Senior Scientist at Pushkov Institute of Terrestrial Magnetism, Ionosphere, and Radio Wave Propagation (IZMIRAN), Russian Academy of Sciences. His research interests include ELF-VLF radio wave propagation, tweak-atmospherics, Earth-ionosphere waveguide, ground penetration radar, deep electromagnetic probing.

E-mail: edemsky@izmiran.ru

IZMIRAN

4 Kaluzhskoye Hwy

Troitsk, Moscow 108840 Russia

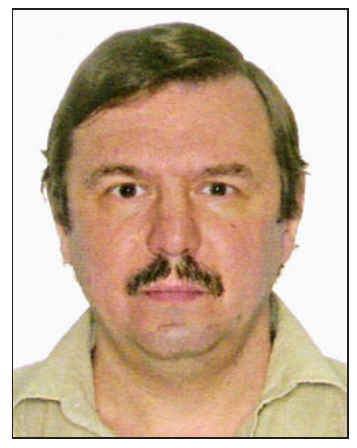

Sergey Gudoshnikov received his Ph.D. from Moscow State University, Department of Physics in 1992. Currently, he is a leading researcher in the Institute of Metallurgy, Ecology and Quality at National University of Science and Technology "MISiS". His research interests include: new magnetic materials, high sensitive magnetic sensors, precise magnetic measurements.

E-mail: gudosh@izmiran.ru

Department of Physical Metallurgy of Non-ferrous,

Rare-earth, and Noble Metals

National University of Science and Technology "MISiS"

4 Leninsky Ave

Moscow, 119049 Russia

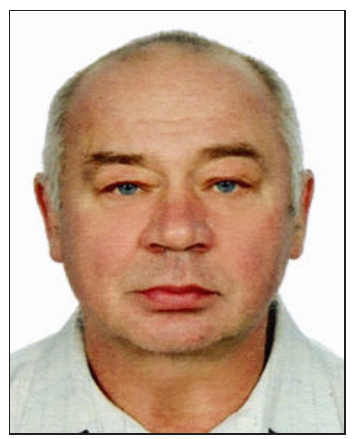

Vladimir Kopeikin received his Ph.D. from the Radiotechnical Faculty of Moscow Power Engineering Institute. Now he is a Senior Researcher of IZMIRAN, Principal Specialist of JSC "Company VNIISMI". Chief designer of Loza GPR series. He is an author and promoter of R\&D works on deep penetration radar, underwater marine radar and holographic subsurface radar.

E-mail: kopeikin@izmiran.ru

IZMIRAN

4 Kaluzhskoye Hwy

Troitsk, Moscow 108840 Russia

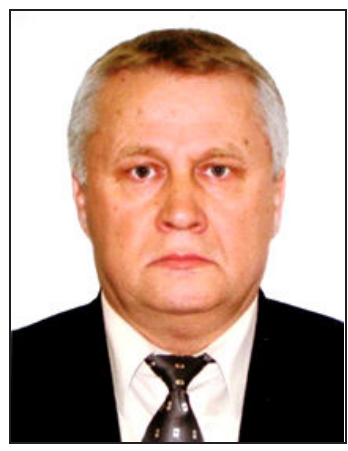

Pavel Morozov is a Senior Researcher of IZMIRAN, Vice Director of JSC "Company VNIISMI". He graduated from Odessa Hydrometeorology Institute, Faculty of Oceanology and Atmospheric Physics, and has Ph.D. in Physics. He is a member of Loza GPR developers' team, author of subsurface radar survey and interpretation methods. He has vast practical experience, teaching and supervision of GPR users.

E-mail: pmoroz5@yandex.ru

IZMIRAN

4 Kaluzhskoye Hwy

Troitsk, Moscow 108840 Russia

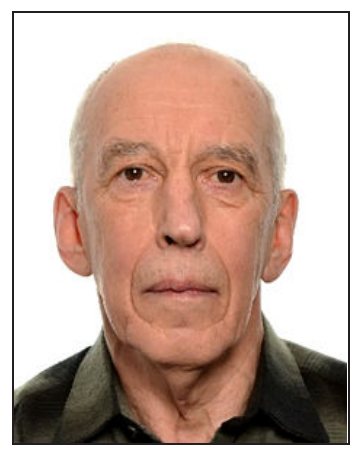

Alexey Popov is a D.Sci., Life Member of IEEE and Head of Radiowave Propagation Department, IZMIRAN. He graduated from Moscow Institute of Physics and Technology in 1964. His expertise includes mathematical physics, computational methods, general diffraction theory, radio wave propagation, ground penetrating radar,

X-ray and fiber optics.

E-mail: popov@izmiran.ru IZMIRAN

4 Kaluzhskoye Hwy

Troitsk, Moscow 108840 Russia

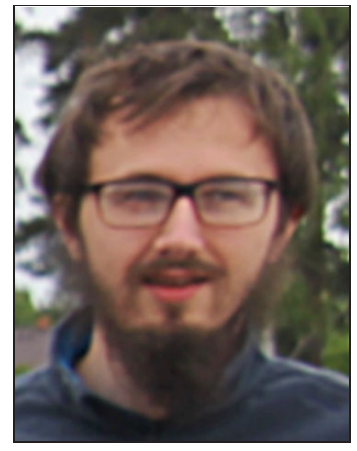

Igor Prokopovich received his M.Sc. in Applied Mathematics and Physics from Moscow Institute of Physics and Technology in 2012. He did his Ph.D. study at IZMIRAN (2014-2017). His expertise is mathematical physics, computational methods, ground penetrating radar, and subsurface microwave holography.

E-mail: prokop21@mail.ru IZMIRAN

4 Kaluzhskoye Hwy

Troitsk, Moscow 108840 Russia 


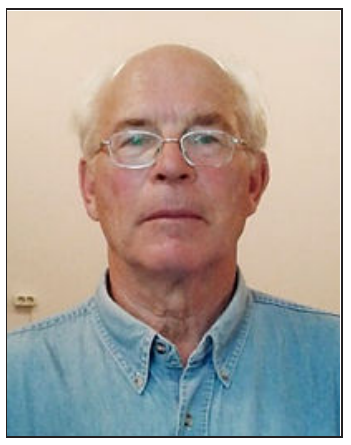

Vladimir Skomarovsky received his Ph.D. from Pushkov Institute of Terrestrial Magnetism, Ionosphere, and Radio Wave Propagation, Russian Academy of Sciences in 1980. $\mathrm{He}$ is currently Senior Scientist in the Laboratory of quantum and cryogenic magnetometry of IZMIRAN. His research interests include magnetic phenomena, magnetic imaging, magnetometry, and amorphous ferromagnetic microwires.

E-mail: vskom@izmiran.ru

IZMIRAN

4 Kaluzhskoye Hwy

Troitsk, Moscow 108840 Russia

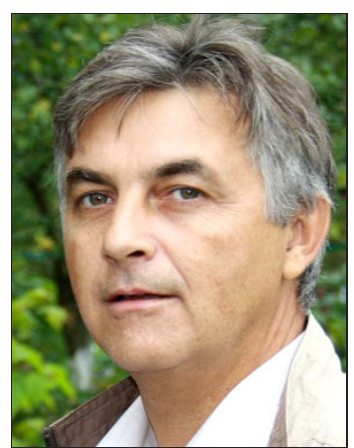

Sergey Merkulov is a Chief Specialist of JSC "Company VNIISMI". He graduated from High Military School of air defence pilots and navigators. $\mathrm{He}$ is the author and developer of "Krot" software for Loza GPR data processing. GPR profiling and surface survey practical schemes. Teaching and supervision of GPR users.

E-mail: merservit@mail.ru JSC "Company VNIISMI" 16/1 Olimpijsky Ave 129090 Moscow, Russia

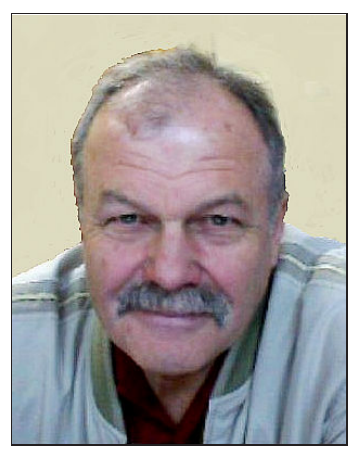

Nikolay Melnik is a Ph.D. and Leading Researcher in Laboratory of Physics of Non-uniform Systems, Lebedev Physical Institute. His expertise includes: Raman spectroscopy, microRaman, high pressure, low and high temperature, resonance Raman scattering. His scientific interests are: disordered and porous materials, nanocrystals, clusters and quantum dots, carbon materials, nanoparticles, diamond-like films, optical properties of films, multilayer structures, and superlattices.

E-mail: melnik@lebedev.ru

FIAN

53 Leninsky Ave

119991 GSP-1 Moscow, Russia

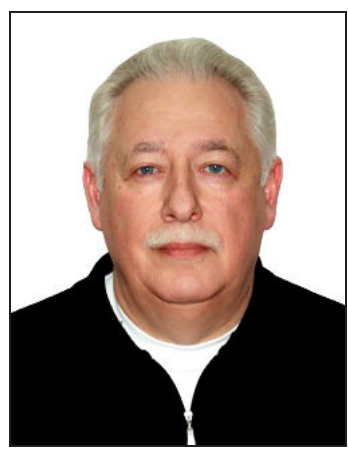

Andrey Berkut is a D.Sci. (Technical Sciences), professor and director general of JSC "Company VNIISMI". He graduated from Moscow Technical University of Communication and Informatics. He is a member of Loza GPR developers' team. Production supervision, marketing, contract activities, development of schemotechnical solutions. GPR application to concrete production in Siberia.

E-mail: lozaberk@yandex.ru

JSC "Company VNIISMI"

16/1 Olimpijsky Ave

129090 Moscow, Russia

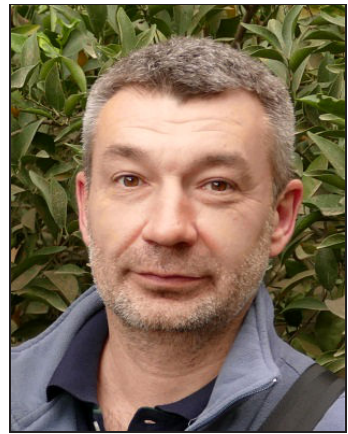

Pavel Vorovsky is a geologist and Leading Researcher, JSC "Company VNIISMI". He graduated from Russian State Geological Prospecting University. $\mathrm{He}$ is an expert in GPR data processing and geological structure characterization, vast practical experience.

E-mail: volga70@inbox.ru JSC “Company VNIISMI" 16/1 Olimpijsky Ave 129090 Moscow, Russia

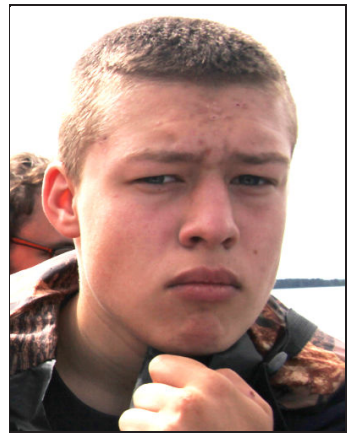

Leonid Bogolyubov is a secondary school student (Troitsk Orthodox School, Moscow Institute of Physics and Technology Phys-Math Correspondence School). He is volunteer member of IZMIRAN-VNIISMI field campaigns.

E-mail: 1.e.o.n.2002@mail.ru

12/56 Solnechnaya

Troitsk, Moscow, 108840 Russia 